\title{
Personal characteristics affecting the biological age of the individual
}

\author{
Tatiana Berezina ${ }^{1, *}$ and Kirill Buzanov ${ }^{2}$ \\ ${ }^{1}$ Moscow State University of Psychology and Education, Moscow, Russia \\ ${ }^{2}$ Research Institute of the Moscow Power Engineering Institute, Moscow, Russia
}

\begin{abstract}
The aim of the research is to study the influence of personality traits and the life path on the rate of biological aging of adults, depending on their gender and age. Methods: diagnostic (questioning the life path, selfesteem of personality, determination of biological age) and statistical (automatic neural networks). Subjects: 987 people (including 575 women) aged 35-70 years from various regions of the Russian Federation. Continuous target variable: relative biological aging of the organism (Biological Age - Proper Biological Age). Continuous input variables: indicators of life path and personality self-esteem. Results: the general factors influencing the rate of biological aging were identified: negative factors that enhance aging - addictions and overwork; and positive factors that slow down aging are having children and professionalization. Personal indicators that changed their sign after a person retired were also found. Women changed their sign from negative to positive for indicators "work at the present time" and "study at the present time", for men - "a positive attitude to pension reform" and professional activities of the types "HumanTechnology", "Human-Sign". The negative strategies of organizing the life path leading to the acceleration of biological aging are highlighted: "forming the addictions and striving for excesses" and "multiplication of the load". Positive strategies are also highlighted: "positive activity strategy" (for women and men of retirement age) and "family strategy" (for men of preretirement age).
\end{abstract}

\section{Introduction}

It is a known fact that people of the same calendar age have different rates of physiological and psychological aging. The rate of individual aging, along with heredity, is also influenced by the characteristics of the external environment (according to T. Berezina) [1], the personality traits of the person himself (according to S. Burke et al.) [2], his eating habits and lifestyle (according to Dorling) [3], and etc. Unlike calendar age, biological age expresses the degree of morphological and psychological development of an individual. The biological age of an organism can correspond to the calendar age, then there is normal relative aging, or it can exceed the calendar age, then aging is considered accelerated, and may be lower than the calendar age - in this case, aging turns out to be slowed down, and this is considered the best option for an individual (according to V.P. Voitenko and A.V. Tokar) [4]. Research

\footnotetext{
*Corresponding author: tanberez@mail.ru
} 
on biological age is relevant due to the expansion of the working period and the pension reform.

\section{Literature review}

Human behavior, his lifestyle, daily routine, attitude to the world affect biological age determined both at the chromosomal level (according to Stellos et al.) [5] and at the level of physiological parameters of the organism (according to Boutari et al.) [6], behavioral manifestations (according to T. Berezina) [7]. As shown by the study of C. Werner et al., changes in the usual behavior of healthy people influenced biological age measured in terms of telomerase activity and telomere length. Lifestyle changes, inclusion of an extreme training in the regime increased the activity of telomerase and other enzymes that are important for cellular aging, regenerative capacity and, therefore, this led to a slowdown in aging (according to Werner et al.) [8].

The intellectual activity of a person, the level of his education, according to most authors, has a positive effect on the characteristics of health and life expectancy. Representatives of intellectual professions living in different countries have biological age indicators lower than their calendar age [9], and they are less susceptible to health deterioration under the influence of retirement stress [10]. Studies in many countries have shown that non-manual workers generally have a higher life expectancy, higher average life expectancy, and a lower likelihood of early death than manual workers (Goh et al., 2015) [11]. For representatives of physical labor, on the contrary, prolonged physical activity of those who are engaged in high-level professional physical activity has a negative effect on health and life expectancy [12].

Brayne C.1, cites the data of an objective study of the relationship between a person's cognitive development and his life expectancy (conducted by D. Snowdon), the relationship between verbal characteristics (knowledge of grammar, spelling, phrase complexity) and the life expectancy was studied in nuns from Catholic monasteries. It has been shown that nuns who had a higher level of verbal development upon admission to a monastery lived longer, more productively, and were less susceptible to Alzheimer's disease [13]. The reasons for the increase in life expectancy in educated people are considered to be cognitive development, constant acquisition of new experience, leading to brain training, and the creation of an optimal functional state of the body [13]. Another explanation is offered by Cutler \& LlerasMuney. They explain this connection through the correct organization of the life path: people with a higher level of education behave differently: they smoke less, drink alcohol in moderate quantity, start taking drugs less often, take care of their weight, exercise in gyms, monitor their health, visit doctors more regularly, have a less risky lifestyle, etc. [14].

Character traits have often become the subject of gerontopsychological research, but different authors sometimes received different data. For example, E. Cornwell and L. Waite consider the positive attitude towards people and sociability as a positive resource that contributes to the extension of individual life [15], although other authors call the opposite qualities - unsociability [16] as an indicator that contributes to life expectancy.

There is no unequivocal opinion about the effect of optimism/pessimism on life expectancy. Researchers at Harvard University have shown a positive effect of optimism. They studied data on the health of more than 70 thousand American women in middle and old age and found that the most optimistic women, on average, died $30 \%$ less often than their peers and colleagues in a depressed mood, in addition, optimists were less likely to have serious illnesses [17]. However, within the framework of The Longevity Project, the authors state that not optimism, but pessimism contributes to an increase in life expectancy, since pessimists are more attentive to their health. Early death was more likely to occur in those 
project participants who are distinguished by a special cheerfulness, a sense of humor and a wide circle of contacts [16].

Interests, lifestyle and bad habits. One of the methods for measuring biological age by behavioral characteristics and physiological changes in the body is the calculation of the Frailty Index [18]. Biomarkers of aging include a group of key indicators that determine the frailty phenotype: low physical activity, slowness, weakness, exhaustion, weight loss, as well as indicators of the cardiovascular and respiratory systems. Many authors associate biomarkers of aging with personality traits and habits, especially bad habits and addictions, which affect not only the frailty index, but also the immunological age of an individual, reducing immunity and accelerating aging [19].

However, there is conflicting data on bad habits. Some authors (Klatsky A.) state the presence of a U-shaped relationship between alcohol consumption and the risk of developing cardiovascular diseases (one of the biomarkers of aging); considering that mild or moderate alcohol consumption reduces the risk of coronary heart disease, myocardial infarction, ischemic stroke and heart failure, and only alcohol abuse is dangerous. [20] A recent study of centenarians without dementia (USA) also showed that most centenarians led a normal lifestyle, they had moderate bad habits, they did not follow special diets, often ate fast food, did not engage in additionally sports, etc. The main thing for them, according to the authors, was an optimistic view of life and social contacts [2].

Summing up the theoretical part, we can say that a large amount of data has been collected on the relationship between characteristics and age parameters (life expectancy, occurrence of diseases). However, there are conflicting data on many personal characteristics. Some authors have shown their positive impact on health, some have negative, some have no influence at all. This is largely caused by the fact that most studies are aimed at studying the effect of a particular indicator on the rate of biopsychological aging. However, personal factors act together, forming a strategy that can be positive (help slow down biological aging) or negative (on the contrary, lead to accelerated aging of the body). At the same time, in the composition of different strategies, individual characteristics can have different effects, up to the fact that they change their sign. Our research is devoted to the study of this assumption.

The purpose of this study: to study the influence of personality traits and the life path on the rate of biological aging of adults, depending on their gender and age group (before and post-retirement age).

\section{Materials and Methods}

Methods:

1. Method "Determination of biological age (BA) according to V.P. Voitenko" [4]. The formulas for measuring biological age include indicators of the activity of the cardiovascular system, the respiratory system, the musculoskeletal system and the balance system, metabolism and psychological indicators (subjective assessment of health). The method also included the statistical norms of the indicator - the proper biological age for each year - PBA. The method is published in detail in [9]

2. The index of relative aging (biological age - proper biological age (BA-PBA)) allows assessing how much a person is older than the statistical age norm in terms of his state of health. Negative values speak about individual youth of a person, and positive values about individual aging in relation to statistical norms. The method is published in detail in [9]

3. Life Path Questionnaire. Original development. In order to assess the features of biography and characteristics of a person's life path, which are most often mentioned in gerontopsychological studies in a positive or negative way (especially those about which there are conflicting data), we have developed a special questionnaire. The subjects were asked to name their profession, education, attitude to pension reform, level of career 
achievements, financial situation, religiosity, place of residence, having a family and children, an object of care, bad habits (smoking, overeating, alcoholism), etc., indicate their hobbies that they had for a long time. Hobbies just had to be listed. When processing the data, we counted the number of hobbies, dividing them into 4 groups: sports, intellectual, creative, subject (handicrafts, crafts, repairs, etc.).

4. Dembo-Rubinstein's personality traits self-assessment method in our modification. We have identified personality traits that are most often associated in the scientific literature with biological aging and life expectancy: aggressiveness, activity, sociability, caring (having an object of care), optimism. To assess these personality traits, schools were developed based on the Dembo-Rubinstein personality self-assessment methodology. The subjects assessed the degree of development of these traits in themselves. During processing, the indicators were reduced to 3 levels: low, medium and high.

5. Method of mathematical statistics: Automatic neural networks (Statistics -12). Since most of the indicators related to age do not have a normal distribution, we chose a statistical method that is independent of the distribution - the method of automatic neural networks. The following parameters were set for creating and training a neural network. Network type: MPP. The minimum number of hidden neurons is 1 . The maximum number of hidden neurons is 1. Networks for training: 20. Networks for saving: 5 (later, 1 network was selected, showing the maximum correspondence to the initial data in the test study). Subsamples size: random. The training network was built at $70 \%$ of the sample size, the control network - at $15 \%$, and the test network - at $15 \%$ of the sample.

The continuous target (analogue of the dependent) variable is the biological aging index (BA-PBA).

Continuous input variables: indicators of life path and personality self-esteem.

Subjects: 987 people, aged 35-70, living in various regions of the Russian Federation, of which: 575 women and 412 men. The sample was formed on a territorial basis. Several territorial entities (areas related to a certain medical or educational institution) were surveyed. Sites were taken in Moscow, Moscow region, Ufa, Republic of North Ossetia. In the Republic of Bashkortostan, all adults aged 35-70 years belonging to this site (to the site of the polyclinic or school) were examined.

All subjects were divided into 4 subgroups: 1) women of pre-retirement age (35-55 years old) - 238 people, 2) women of retirement age (56-70 years old) - 337 people, 3 ) men of preretirement age (35-60 years old) - 289 people, 4$)$ men of retirement age (61-70 years old) 124 people.

\section{Results}

At the first stage, we conducted a study of the effect of personal characteristics on the biological aging index in women of pre-retirement age using the method of automatic neural networks. For each personality trait, its proportion was obtained, which it occupies in a given neural network, where the biological aging index was used as a target indicator. We ranked the personality traits that accelerate aging (have a positive weight) and that slow down aging (have a negative weight). Thus, two strategies were obtained: negative and positive (both of them are presented in Table 1.

Table 1. The proportions of personal traits affecting the biological aging index for women of preretirement age.

\begin{tabular}{|l|c|l|c|}
\hline \multicolumn{2}{|c|}{ Accelerates biological aging. } & \multicolumn{2}{c|}{ Slows down biological aging. } \\
\hline \multicolumn{1}{|c|}{ Indicators } & Proportions & \multicolumn{1}{c|}{ Indicators } & Proportions \\
\hline Overeating & $\mathbf{0 . 4 2 0 8 0 3}$ & Optimism & $\mathbf{- 0 . 3 0 6 4 1 5}$ \\
\hline Financial position & $\mathbf{0 . 2 2 6 1 6 3}$ & Activity H-N & $\mathbf{- 0 . 3 0 5 2 6 3}$ \\
\hline
\end{tabular}




\begin{tabular}{|l|c|l|c|}
\hline $\begin{array}{l}\text { Work at the present } \\
\text { time }\end{array}$ & $\mathbf{0 . 1 6 8 1 5 3}$ & Activity H-AI & $\mathbf{- 0 . 2 9 8 7 9 4}$ \\
\hline Aggressiveness & $\mathbf{0 . 1 3 8 8 2 3}$ & Caring (object of caring) & $\mathbf{- 0 . 2 9 4 9 6 2}$ \\
\hline Alcohol consumption & $\mathbf{0 . 1 1 5 3 7 6}$ & Sociability & $\mathbf{- 0 . 2 5 6 6 8 1}$ \\
\hline Having a family & $\mathbf{0 . 1 0 9 6 5 3}$ & Mobility & $\mathbf{- 0 . 2 1 9 6 8 7}$ \\
\hline $\begin{array}{l}\text { Study at the present } \\
\text { time }\end{array}$ & 0.070221 & Activity, purposefulness & $\mathbf{- 0 . 2 0 8 3 6 3}$ \\
\hline Smoking & 0.062576 & $\begin{array}{l}\text { Positive attitude towards } \\
\text { pension reform }\end{array}$ & $\mathbf{- 0 . 1 2 9 4 0 5}$ \\
\hline Career & 0.061692 & Activity H-S & $\mathbf{- 0 . 1 1 4 1 2 5}$ \\
\hline Subject hobbies & 0.046892 & Having children & $\mathbf{- 0 . 1 1 3 0 0 7}$ \\
\hline Education & 0.008154 & Activity H-T & -0.093189 \\
\hline Religiosity & 0.009415 & Creative hobbies & -0.089897 \\
\hline & & Activity H-H & -0.077121 \\
\hline & & Intellectual hobbies & -0.021693 \\
\hline & & Sports hobbies & -0.013881 \\
\hline & & Residence in a large city & -0.006379 \\
\hline
\end{tabular}

Indicators with a high proportion that have a significant effect on biological aging are highlighted in bold.

As can be seen from the table, analysis by means of automatic neural networks made it possible to identify two possible ways of personal organization of life for working women:

1 - leading to the acceleration of biological aging, it includes bad habits (overeating, drinking alcohol), energy-intensive activities (work, family, study, achievement of material wealth) and aggressiveness as a personality trait. We call this strategy "forming addictions and striving for excesses".

2 - leading to a slowdown in biological aging, it includes: performance indicators (qualified work in the areas of Human-Nature, Human-Artistic Image, Human-Sign, a positive attitude towards pension reform), the presence of children and other objects of care, a positive attitude towards life (optimism, activity, dedication) and mobility (the presence of moving). We called this method "positive activity strategy".

At the second stage, we studied the influence of personality traits on the biological aging index in women of retirement age using the method of automatic neural networks (detailed description above). Factors accelerating aging and slowing it down are presented in Table 2.

Table 2. The proportions of personal traits affecting the biological aging index for women of retirement age.

\begin{tabular}{|l|c|l|c|}
\hline \multicolumn{2}{|c|}{ Accelerates biological aging. } & \multicolumn{2}{c|}{ Slows down biological aging. } \\
\hline \multicolumn{1}{|c|}{ Indicators } & Proportions & \multicolumn{1}{c|}{ Indicators } & Proportions \\
\hline Residence in a large city & $\mathbf{0 . 7 4 0 9 2 7}$ & Activity H - T & $\mathbf{- 0 . 5 5 1 3 0 1}$ \\
\hline Overeating & $\mathbf{0 . 4 6 6 7 1 2}$ & $\begin{array}{l}\text { Study at the present } \\
\text { time }\end{array}$ & $\mathbf{- 0 . 4 1 1 5 7 8}$ \\
\hline Aggressiveness & $\mathbf{0 . 2 7 2 4 5 1}$ & Mobility & $\mathbf{- 0 . 4 0 1 2 7 6}$ \\
\hline Religiosity & $\mathbf{0 . 2 6 3 0 0 1}$ & Activity H-H & $\mathbf{- 0 . 3 5 1 9 6 8}$ \\
\hline Financial position & $\mathbf{0 . 1 4 8 8 5 9}$ & Optimism & $\mathbf{- 0 . 3 0 9 0 1 1}$ \\
\hline Having a family & $\mathbf{0 . 1 4 7 8 6 6}$ & Subject hobbies & $\mathbf{- 0 . 2 9 8 2 5 2}$ \\
\hline Creative hobbies & 0.096862 & Activity H-N & $\mathbf{- 0 . 2 8 3 3 4 8}$ \\
\hline Caring (object of caring) & 0.046691 & Activity H-S & $\mathbf{- 0 . 1 7 9 6 4 7}$ \\
\hline Activity, purposefulness & 0.036921 & Education & $\mathbf{- 0 . 1 8 4 4 5 1}$ \\
\hline Intellectual hobbies & 0.001803 & Sports hobbies & $\mathbf{- 0 . 1 7 4 8 2 0}$ \\
\hline & & Smoking & $\mathbf{- 0 . 1 3 5 6 3 9}$ \\
\hline & & $\begin{array}{l}\text { Work at the present } \\
\text { time }\end{array}$ & $\mathbf{- 0 . 1 3 2 1 2 9}$ \\
\hline & Having children & $\mathbf{- 0 . 1 0 2 2 1 5}$ \\
\hline
\end{tabular}




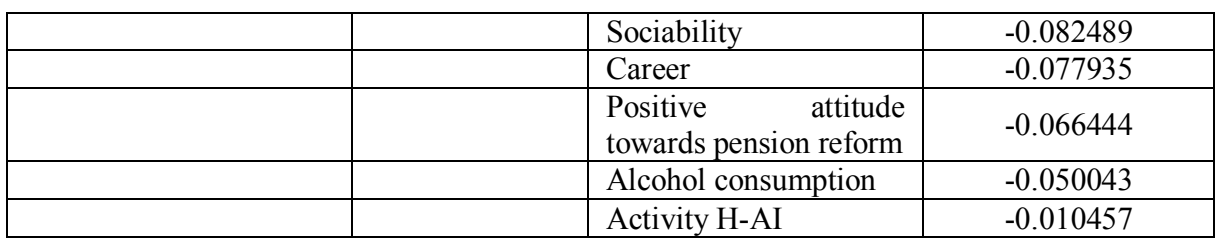

Indicators with a high proportion that have a significant effect on biological aging are highlighted in bold.

As can be seen from the table, analysis by means of automatic neural networks made it possible to single out two possible ways of personal organization of life for women of retirement age:

1 - leading to the acceleration of biological aging. Bad habits include: overeating, energyintensive activities (living in a large city, family, achieving material wealth), aggressiveness as a personality trait, religiosity. It is also a strategy of "forming addictions and striving for excesses", but the proportion of psychological addictions (religiosity) increases and physiological ones decreases.

2 - leading to a slowdown in biological aging, it includes most of the performance indicators, including energy-intensive ones (work at the present time, study at the present time, any qualified activity), the presence of children, education, the emergence of hobbies (sports and subject ones). Of the positive personality traits, optimism remained. It is also a "positive activity strategy". But along with work, it also includes hobbies.

At the third stage, we studied the influence of personality traits on the biological aging index in men of pre-retirement age using the method of automatic neural networks (detailed description above). The results are shown in Table 3.

Table 3. The proportions of personal traits affecting the biological aging index for men of preretirement age.

\begin{tabular}{|c|c|c|c|}
\hline \multicolumn{2}{|c|}{ Accelerates biological aging. } & \multicolumn{2}{|c|}{ Slows down biological aging. } \\
\hline Indicators & Proportions & Indicators & Proportions \\
\hline Sports hobbies & 23.4577 & Career & -16.7685 \\
\hline Activity H-S & 17.5459 & Study at the present time & -15.8959 \\
\hline Activity H-N & 15.3347 & Having children & -12.7660 \\
\hline Creative hobbies & 14.9615 & Religiosity & -9.9967 \\
\hline $\begin{array}{l}\text { Positive attitude } \\
\text { towards pension reform }\end{array}$ & 13.8823 & Having a family & -8.0059 \\
\hline Mobility & 13.4476 & Activity $\mathrm{H}-\mathrm{H}$ & -7.2442 \\
\hline Financial position & 10.5558 & Activity, purposefulness & -4.1668 \\
\hline Activity H-T & 6.6708 & Aggressiveness & -4.1373 \\
\hline Sociability & 6.4990 & Subject hobbies & -3.7313 \\
\hline Education & 6.1057 & Residence in a large city & -2.8980 \\
\hline Intellectual hobbies & 5.0097 & Work at the present time & -2.1406 \\
\hline Smoking & 3.5844 & Caring (object of caring) & -0.7316 \\
\hline Activity H-AI & 3.5408 & & \\
\hline Optimism & 3.3736 & & \\
\hline Overeating & 2.6746 & & \\
\hline Alcohol consumption & 0.2202 & & \\
\hline
\end{tabular}

Indicators with a high proportion that have a significant effect on biological aging are highlighted in bold.

As can be seen from the table, analysis by means of automatic neural networks made it possible to single out two possible ways of personal organization of life for men of preretirement age: 
1 - leading to the acceleration of biological aging, it includes energy-intensive activities (achieving a high financial position) and almost all hobbies (sports and intellectual ones), moving, qualified work in the areas of Human-Nature, Human-Technology, Huan-Sign, a positive attitude to pension reform, education and sociability. This is a "load multiplication" strategy.

2 - leading to a slowdown in biological aging, it includes characteristics (having a family, children, career), studies at the present time, and qualified work in the field of HumanHuman. This is the strategy of a self-realized "domestic" man: "family and child orientation".

At the fourth stage, we studied the influence of personality traits on the biological aging index in men of retirement age using the method of automatic neural networks (detailed description above). Factors accelerating aging and slowing it down are presented in Table 4.

Table 4. The proportions of personal traits affecting the biological aging index for men of retirement age.

\begin{tabular}{|l|c|l|c|}
\hline \multicolumn{2}{|c|}{ Accelerates biological aging. } & \multicolumn{2}{c|}{ Slows down biological aging. } \\
\hline \multicolumn{1}{|c|}{ Indicators } & Proportions & \multicolumn{1}{c|}{ Indicators } & Proportions \\
\hline Smoking & $\mathbf{1 . 0 1 5 1 2}$ & Activity H-AI & $\mathbf{- 1 . 5 0 3 6 9}$ \\
\hline Financial position & $\mathbf{0 . 6 6 1 3 6}$ & $\begin{array}{l}\text { Positive attitude towards } \\
\text { pension reform }\end{array}$ & $\mathbf{- 1 . 0 0 3 8 3}$ \\
\hline Overeating & $\mathbf{0 . 4 5 7 5 3}$ & Activity H-T & $\mathbf{- 0 . 8 9 8 2 3}$ \\
\hline Intellectual hobbies & 0.35897 & Aggressiveness & $\mathbf{- 0 . 8 3 3 9 4}$ \\
\hline Having a family & 0.32910 & Activity H-N & $\mathbf{- 0 . 8 2 9 4 8}$ \\
\hline Career & 0.32258 & Optimism & $\mathbf{- 0 . 7 1 1 0 8}$ \\
\hline Residence in a large city & 0.28310 & Activity H-S & $\mathbf{- 0 . 5 4 0 3 0}$ \\
\hline Activity purposefulness & 0.25019 & Work at the present time & $\mathbf{- 0 . 4 2 1 0 4}$ \\
\hline Creative hobbies & 0.24659 & Activity H-H & -0.31480 \\
\hline Sports hobbies & 0.23425 & Alcoholism & -0.19476 \\
\hline Study at the present time & 0.15645 & Subject hobbies & -0.18124 \\
\hline Education & 0.12033 & Having children & -0.14872 \\
\hline Sociability & 0.02485 & Mobility & -0.14338 \\
\hline & & Religiosity & -0.14241 \\
\hline & & Caring (object of caring) & -0.07429 \\
\hline
\end{tabular}

Indicators with a high proportion that have a significant effect on biological aging are highlighted in bold.

As can be seen from the table, analysis by means of automatic neural networks made it possible to single out two possible ways of personal organization of life for men of retirement age:

1 - leading to the acceleration of biological aging, it includes bad habits (overeating and smoking) and energy-intensive activities to achieve material wealth. This strategy is "forming addictions and striving for excesses", and more often, it is harmful addictions that are formed.

2 - leading to a slowdown in biological aging, it includes most performance indicators (any qualified activity) and a positive attitude towards pension reform. This is a positive activity strategy, it includes the continuation of work in retirement and a positive attitude towards pension reform.

\section{Discussion}

There are conflicting data in the literature regarding the influence of many personality traits on biopsychological aging. Our study was carried out with the aim of clarifying the possible causes of this phenomenon through the use of an individual and typological approach and the use of modern methods of statistical data processing. We believed that, firstly, the influence 
of personality traits is mediated by the type of person (in particular, his gender and age) and, secondly, many personality traits are linked together, forming a system or strategy. As our study has shown, a very small number of personal characteristics can be called absolutely negative, i.e. they affect biological aging both in men and women, both in pre-retirement and retirement ages. In fact, in our study, only 2 groups of negative factors, common to all surveyed categories of subjects, were distinguished: these are addictions (bad habits) and overwork (energy-consuming activities, among which the indicator "financial position" turned out to be consistently negative). In men, the negative effect of smoking and overeating begins to be more pronounced upon retirement (after age 61), but the negative effect of alcohol consumption, on the contrary, disappears. In women, the harm from addictions is more pronounced before retirement, and after 56 years, the negative effect decreases up to the point that smoking falls into the group of weakly positive factors. The fact that bad habits reduce their harmfulness in old age has been described in the literature, including by us earlier, and it has an explanation. With age, carriers of pronounced bad habits usually die out, only those who have bad habits are either absent or present to a weak degree. This does not apply to overeating, it retains its negative impact for all age groups [21].

It turned out to be unexpected for us that the indicator "Financial position" was included in all negative strategies. In the literature, data on that material wealth contributes to both the extension of life and the preservation of health are much more common. It was classified as negative only by the authors of the concept of two types of life organization (A and B). Within the framework of this concept, it is not the wealth itself that turns out to be negative, but the ways to achieve it (type A), requiring the exertion of all forces, competitive behavior, stressful experiences, which negatively affects work of the cardiovascular system [22]. We believe that in Russia in the modern period, the financial situation is unambiguously a consequence of the pronounced behavior of type A, which led to the fact that this indicator began to negatively affect the biological age of a person.

Common positive factors that slow biological aging in men and women are children and professionalization. The presence of children is a factor that is favorable specifically for Russia, which was established in a recent twin study, where it was shown that having children leads to an increase in life expectancy, and this was explained by the fact that in Russia, as a rule, elderly parents live with their children, who provide care and help financially. For example, for Canada, this indicator did not matter. For them it was shown that a woman's life expectancy depends only on the ability to have children (but not on their presence or number) [23]. In general, our research confirms the favorableness of the factor "having children" for Russia.

As for labor activity, this indicator is ambiguous. On the one hand, we see that almost any type of profession is favorable for women of any age and men over 61 years old. But, on the other hand, we also observe that many indicators related to work (work at the present time, career, financial position) negatively affect biological age. We believe that we are dealing with two factors here. One of them is favorable: professionalization, which includes the acquisition of vocational education, retraining, and professional activities. The second factor is unfavorable: overwork - doing difficult work, overworking, fighting for career growth, a combination of several types of activity (work and study, work and family) - leads to an acceleration of biological aging of the body. Fatigue is most pronounced in pre-retirement adult men. Therefore, almost all types of activity (most hobbies, work, travel, etc.) are unfavorable for them. Almost all types of professions in men at this age increase the overload and worsen the state of the body (except for the "Human-Human" type). This group of men is also characterized by a negative attitude towards pension reform. Usually, a positive attitude towards pension reform acts as a factor motivating to activity, and in this group, due to general overwork, an additional increase in the volume of work performed worsens the biological state of the body. 
Let's consider also the indicators that change sign after a person retires. For women, the indicators "work at the present time" and "study at the present time" changed their sign from negative to positive after retirement. We explain this by the action of the same meta-factor: overwork, affecting women of working age. After retirement, the overall load decreases, fatigue disappears, and the positive effect of both work and study begins to appear. For men, the following indicators changed their sign to positive after retirement: a positive attitude to the pension reform, as well as professional activities of the types "Human-Technology", "Human-Sign". Probably, as in women, this is due to a decrease in load and restoration of the action of initially positive factors.

Some indicators move from the category of insignificant to significant with age. Among women of pre-retirement age, the biological age was insignificantly influenced: education, hobbies, place of residence, religiosity. After retirement, education, the presence of subject and sports hobbies begin to slow down the rate of aging, and religiosity and living in a large city - to accelerate it.

Among men of pre-retirement age, the biological age was insignificantly influenced by the presence of a profession of the type "Human-Artistic Image", aggressiveness, optimism, and work at the present time. After retirement, all of these indicators begin to have a beneficial effect on the body, slowing down individual aging. We believe that the reason for these transformations is a change in the lifestyle of a person in retirement, a decrease in his overall workload, and an increase in free time.

In the light of the obtained data, it is also possible to propose an explanation for the conflicting data from the scientific literature described in the review. For example, the predominance of people of pre-retirement age in the sample will lead to the fact that sociability and optimism will be considered unfavorable indicators, and if people of postretirement age predominate, on the contrary, the favorableness of these qualities will be shown.

\section{Conclusions}

There are two negative (addictions and overwork) and two positive (having children and professionalization) personality factors that affect the rate of biological aging in adults (3570 years old). Addictions include bad habits (overeating, smoking, alcohol consumption, the greatest proportion - overeating), as well as certain behavioral excesses (aggressiveness, striving for success at any cost, etc.) in some categories of subjects. Overwork includes doing difficult work, overworking, struggling for career advancement, combining several activities (work and study, work and family). The presence of children is a positive factor specifically for our country. It helps to slow down the rate of biological aging, since in Russia, as a rule, elderly parents live with their children, who provide care and help financially. Professionalization includes the acquisition of vocational education, retraining, professional activities, skilled labor.

Many personal traits affect the biological age of a person through the prism of his individuality, in particular, depending on his gender and age, and they change their sign after a person leaves for a well-deserved rest. For women, the indicators "work at the present time" and "study at the present time" changed their sign from negative to positive after retirement. For men, the following indicators changed their sign to positive after retirement: a positive attitude to the pension reform, as well as professional activities of the types "HumanTechnology", "Human-Sign". This is due to a decrease in the overall load after retirement and the restoration of a positive activity effect.

\section{Acknowledgements}


The author expresses gratitude to the young researchers who took part in the collection of empirical material: Buzanov K.E., Golubev I.D., Zinatullina A.M., Isyandavletova F.S., Kalaeva A.A., Sedykh Yu. P., Melnik V.P., Terekhina A.V., Faskhutdinova Yu. F.

This work was supported by Russian Science Foundation, No. 19-18-00058

\section{References}

1. T.N. Berezina, Voprosy Psikhologii 2017(2), 79-88 (2017) https://www.scopus.com/record/display.uri?eid=2-s2.085026631075\&origin=inward\&txGid=b17fb696717703e $216 \mathrm{f} 7001 \mathrm{~b} 67829758$

2. S.N. Burke, E.C. Mormino, E.J. Rogalski et al., Neurobiology of Aging 83, 140-144 (2019) https://doi.org/10.1016/j.neurobiolaging.2019.03.023

3. L.J. Dorling, C.K. Martin, L.M. Redman, Ageing Res Rev. 64 (2020) DOI: $10.1016 /$ j.arr.2020.101038

4. V.P. Voitenko, A.V. Tokar, Exp. Aging. Res. 9(4), 239-244 (1983) https://doi.org/10.1080/03610738308258458

5. K. Stellos, I. Spyridopoulos, European Heart Journal 40(1), 47-49 (2019) https://doi.org/10.1093/eurheartj/ehy707

6. C. Boutari, C.S. Mantzoros, Endocrinology and Metabolism 32(4), 422 (2017) http://dx.doi.org/10.3803/EnM.2017.32.4.422

7. T. Berezina, E3S Web of Conferences 210, 17032 (2020) https://doi.org/10.1051/e3sconf/202021017028

8. C.M. Werner, A.Hecksteden, A. Morsch et al., European Heart Journal 40(1), 34-46 (2019) DOI: 10.1093/eurheartj/ehy585

9. T.N. Berezina, N.N. Rybtsova, S.A. Rybtsov, European Journal of Investigation in Health, Psychology and Education 10(3), 749-762 (2020) https://doi.org/10.3390/ejihpe10030055/

10. T.N. Berezina, N.N. Rybtsova, S.A. Rybtsov et al., Journal of Modern Foreign Psychology 9(1), 8-21 (2020) doi:10.17759/jmfp.2020090101

11. J. Goh, J. Pfeffer, S. Zenios, Health Aff (Millwood) 34(10), 1761-8 (2015) https://doi.org/10.1377/hlthaff.2015.0022

12. P. Coenen, M.A. Huysmans, A. Holtermann et al., Br. J. Sports Med. 52(20), 1320-1326 (2018) DOI: 10.1136 / bjsports-2017-098540

13. C. Brayne, International Journal of Epidemiology 31(4), 879 (2002) https://doi.org/10.1093/ije/31.4.879/

14. C. Lopez-Otin, M.A. Blasco, L. Partridge et al., Cell. 153, 1194-1217 (2013) DOI: $10.1016 /$ j.cell.2013.05.039

15. E.Y. Cornwell, L.J. Waite, Journal of Health and Social Behavior 50(1), 31-48 (2009) doi:10.1177/002214650905000103

16. H.S. Friedman, L.R. Martin, The longevity project: Surprising discoveries for health and long life from the landmark eight-decade study (Hudson Street Press/Penguin Group, USA, 2012) https://doi.org/10.1111/j.1728-4457.2012.00481.x

17. E.S. Kim, K.A. Hagan, F. Grodstein et al., Am. J. Epidemiol. 185(1), 21-29 (2017) https://doi.org/10.1093/aje/kww182

18. A. Mitnitski, J. Collerton, C. Martin-Ruiz et al., BMC Med 13, 161 (2015) https://doi.org/10.1186/s12916-015-0400-x 
19. N. Rybtsova, T. Berezina, A. Kagansky, S. Rybtsov, Biomedicines 8(12), 615 (2020) https://doi.org/10.3390/biomedicines8120615

20. A.L. Klatsky, Y. Li, H.N. Tran et al., Perm J. Spring. 19(2), 28-34 (2015) DOI: $10.7812 / \mathrm{TPP} / 14-189$

21. T. Berezina, E3s Web of Conferences 210, 17032 (2020) https://doi.org/10.1051/e3sconf/202021017032

22. O. Stavrova, D. Ehlebracht, Eur. J. Pers. 33, 52-71 (2019) https://doi.org/10.1002/per.2183

23. L. Manzoli, P. Villari, G. Pirone, A. Boccia, Soc. Sci. Med. 64(1), 77-94 (2007) DOI: 10.1016 / j.socscimed.2006.08.031 